\title{
AN OVERVIEW OF AUTOMATED MANUFACTURING FOR COMPOSITE MATERIALS
}

\author{
Andrew Loeliger and Erfu Yang \\ Design, Manufacturing and Engineering \\ Management \\ University of Strathclyde \\ Glasgow G1 1XJ, Scotland, UK \\ e-mail: \{andrew.loeliger, erfu.yang*\}@strath.ac.uk \\ *Corresponding author.
}

\author{
Iain Bomphray \\ Lightweight Manufacturing Centre \\ National Manufacturing Institute Scotland \\ Block E, Westway Business Park \\ Porterfield Road, Renfrewshire \\ PA4 8DJ, Scotland, UK \\ e-mail: iain.bomphray@strath.ac.uk
}

\begin{abstract}
This paper aims to present an overview of composite materials with the focus on automated manufacturing. First, it provides an initial understanding of what composite materials are, their different classifications and their advantages and disadvantages. Then, manufacturing automation is discussed along with the different classifications of robot that are commonly used and the advantages and disadvantages of automation. Market analysis shows that three industries of interest due to their advancements in composite and automated manufacturing are the automotive, aerospace and marine industries. A review of companies currently implementing composite materials and their use of automated manufacturing within these specific industries has therefore been carried out. Finally, research challenges are highlighted, along with directions for future research.
\end{abstract}

Keywords-review; automated manufacturing, composite materials, robots, automotive, aerospace.

\section{INTRODUCTION}

Two significant growth areas in industry are manufacturing automation and the use of composite materials. The global automation market is forecast to grow from $\$ 76.83$ billion in 2019 to $\$ 114.17$ billion by 2025 [1]. The use of composite materials is also predicted to rise significantly from $\$ 28$ billion in 2016 to $\$ 42$ billion in 2022 [2].

Automated manufacturing in this study refers to the implementation of robots within the production line that do not require the control of a human operator. Human workers are not required as the robot systems are designed to carry out a set of tasks independently by themselves or part of a group of robots. With the implementation of automated manufacturing, an increase in production throughput due to the reduction in time and increase in quality and reproducibility can be experienced. A composite material is defined as the amalgamation of two or more differing materials, resulting in a new material. This new material can display different properties to those of the original materials used in its creation [3]. Overall, the new material will have improved properties compared to the original separate materials. Although the composite material has been merged, the materials remain distinct from one another, making composite materials fundamentally different from solids, solutions and mixtures where the materials cannot be separated [4]. This paper will discuss the methods of automation used in specific industries when working with composite materials and will focus on current approaches and issues within this field.

\section{UNDERSTANDING COMPOSITES}

\section{A. Composite Classification}

Composite materials are created using two key elements; the matrix and the reinforcement [4]. The matrix is implemented to bind the reinforcement together and maintain the required shape of the material. The reinforcement is implemented to provide the structural strength and stiffness required by the composite material. Additionally, the reinforcement enhances the physical properties of the matrix [3].

Composites can be classified based upon the matrix or the reinforcement used [3-5]. The matrixes can be categorised into three sub sections; Ceramic Matrix Composites (CMCs), Metal Matrix Composites (MMCs) and Polymer Matrix Composites (PMCs). The reinforcement can be separated into three sub sections; Fibre, Particle and Laminar.

The most common methods for the combination of matrix and reinforcement components in a composite material are the hand lay-up and spray-up processes [3][4]. Both are very labour intensive procedures. The lay-up process involves the constituent parts being layered by hand and compressed while the spray-up process involves the composite being sprayed onto a surface by hand and layers being gradually built up. Both methods rely on human accuracy and can result in uneven application and areas of reinforcement with incorrect amounts of matrix. Composite materials need to be cured to set the matrix with the reinforcements together. This curing is done in an autoclave which heats the material under pressure.

Two separate methods which help to reduce the time consumption and manual labour issues, while increasing quality and consistency, are the use of preform and prepreg composites [6]. Preform is a technique of shaping the reinforcement into the shape required before the matrix is added. It can be formed into the shape by weaving or directly using a mould. The matrix can then be introduced to the mould containing the shaped reinforcement under pressure. This allows the accurate control of the amount of 
matrix added to the composite. The advantage of prepreg sheets is that they are composed of a predefined mix of matrix and reinforcement. The prepreg sheets therefore do not require the user to apply the matrix which ensures the correct ratio of matrix and reinforcements across the entire material. The prepreg is formed into the required shapes for the application and then cured.

\section{B. General Advantages \& Disadvantages of Composites}

Many papers agree that there are multiple advantages in the use of composite materials [4][7][8]. All papers highlight one of the key advantages as being the production of lightweight composite materials. The weight to strength ratio is greater than that of the standard materials that the composites are designed to replace. Another main advantage, discussed in many papers, is that composites, due to their composition, are easier to form into complex geometric shapes. Pliable, malleable composite materials are available that are versatile and can be moulded therefore requiring less labour intensive machining methods. Papers agree that composite materials and the raw materials used to develop them are often costly. Research and development are required to create lower cost solutions [5][7][9].

\section{MANUFACTURING AUTOMATION}

\section{A. Robot Classification}

Robots can be classified depending on their work envelope which describes the places in a $3 \mathrm{D}$ space that can be reached by the robot's wrist. It is important to understand the classification of robots so that the optimal robot configuration can be selected for an automated manufacturing process. Two main types of joint used are prismatic and revolute. Prismatic joints consist of movement along an axis, whereas revolute consist of movement about an axis. There are six different classifications of robot; Cartesian, Cylindrical, Spherical, SCARA, Articulated and Parallel. Examples of the classifications can be seen in Figure 1 going left to right. All robot types can be created using three joints.

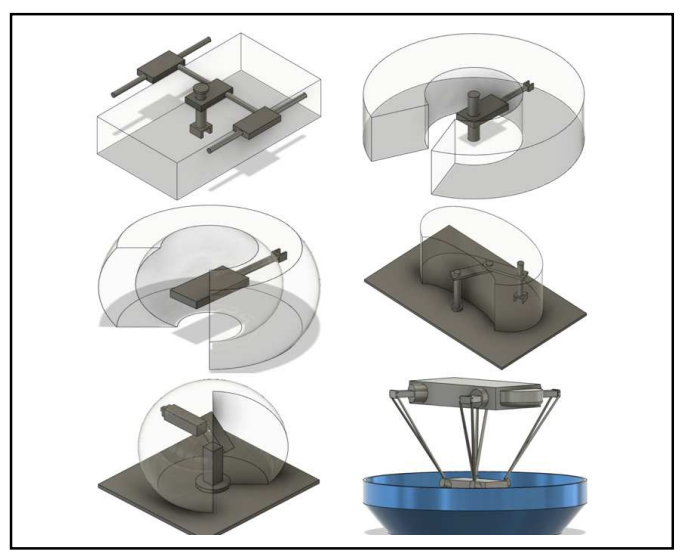

Figure 1 - Robot Classifications

Cartesian, also known as Planar, robots are constructed of three prismatic joints and work as a gantry system. The robot will move to carry out tasks such as pick and place, arc welding and handling tools on an assembly line.

Cylindrical robots implement one revolute joint and two prismatic joints to move. A robot arm can move along an axis, rotate around the same axis and extend and retract along a separate axis. Examples of use include die casting, assembly and spot welding.

Spherical, also known as Polar, robots contain two revolute joints and one prismatic joint. A robot arm can rotate around an axis, rotate around a perpendicular axis and extend and retract along a separate axis. Examples of use include arc welding, spot welding and die casting.

SCARA (Selective Compliance Articulated Robot Arm) robots are designed using two revolute joints and one prismatic arm. A robot arm can rotate around an axis, rotate around a second parallel axis further along the robot arm and extend and retract along a third parallel axis at the end of the robot arm. Examples of use include pick and place and handling tools on an assembly line.

Articulated robots deploy three revolute joints to carry out tasks. A robot arm can rotate around an axis, rotate around a second parallel axis further along the robot arm and rotate around a third axis perpendicular to the second axis positioned further along the robot arm. Examples of use include spray painting, arc welding and part assembly.

Parallel robots require more than three joints and can be made up of revolute and/or prismatic joints. Examples of use include vehicle simulators and satellite trackers.

For full position and orientation utilisation, 6 DOF (Degrees Of Freedom) are required. Occasionally, more than 6 DOF are required by a robot arm. This is to work around obstacles or constraints experienced in the robot arm's work envelope.

\section{B. Cobots}

A new form of robot has been making its way into the production line. These robots are called Collaborative Robots, or Cobots for short. The primary use for Cobots is to create human/robot collaboration in a production line. As a majority of Cobots are lightweight and repositionable, this makes them a good stepping-stone into the automation of a factory [10]. Cobots are able to provide the strength and power of a robotic system to a worker who can make decisions based on situations that occur.

The concept of Cobots and papers covering them have grown exponentially in the last few years, as has the market for Cobots within a production line. With the increase in papers being produced and interest for production lines, it seems highly likely that Cobots will take the forefront of robot-human interaction in the next few decades.

As Cobots are still somewhat new, there is room to improve and branch out into further research. One area of research is to try and enhance the payload that Cobots can manage as current systems typically cannot handle the same weights as standard robots [11]. Another area of interest is the implementation of additional visual feedback systems allowing the Cobot to incorporate extra safety features, tracking workers around it, or alternative methods to locate components it requires to interact with. The visual system could also provide a method for the Cobot to predict the movement of workers nearby, increasing its effectiveness. A related point of interest is the deployment of force or pressure sensors on the Cobot. The sensors could 
be used to record and repeat the force or pressure required to be exerted to complete a task, allowing fine control and delicate operations to be undertaken [12].

\section{Automation - General Advantages \& Disadvantages}

With the introduction of automation into a production line, problems and disadvantages of the new system can occur. Several problems have been highlighted including cost, limited tasks and loss of jobs [13]. As with the investment into any new system, a sizeable financial outlay will be required to purchase, install, set up and train workers on how to use the machinery [14].

Although the robots are programmed to carry out their tasks, they are limited due to their programming. If new or unexpected problems or situations arise, the robot may not be able to react properly or in time [15]. This could cause knock-on issues throughout the production line, producing faulty products or damage to machinery. The robots also have difficulties quickly and easily changing to a new setup for a different task or product [14].

There are many benefits associated with automated manufacturing which is why so many companies are investing in the required technologies. The main benefits driving the next generation of automated production lines are; cost, productivity, quality and employment [16].

Initial expenditure is required for new robots to be added to the production line although, ultimately, the benefits experienced due to the new system should eclipse the cost factor.

When a robot carries out a task, the time required for completion is often much quicker than when a human worker carries out the same procedure. As robots do not need time off, the machines can be kept running for longer periods, therefore increasing the productivity and quantity of product created.

A robot is more efficient at carrying out tasks as it can reproduce the same high-quality product time and time again without getting tired. This allows the high standard of production to be maintained.

Throughout history it has been a concern that adding automation to production lines causes a reduction in labour requirements. While it is true that certain jobs are taken over by robots, it is also the case that new jobs are created replacing those lost due to automation. An example is the introduction of the Personal Computer, PC [13]. The PC displaced many jobs as they were transferred to a digital form but went on to generate 15.8 million new jobs in the US alone. Employees can be retrained to work in other areas of the production line or be trained to operate and maintain the new machines.

\section{AutOMATEd MANUFACTURING WITH COMPOSITES - AN INDUSTRY OVERVIEW}

All market analysts predict a growth in composite material use across many industries [2]. Industries of particular interest, due to their advances in manufacturing automation, are automotive, aerospace and marine, as seen in Figure 2.

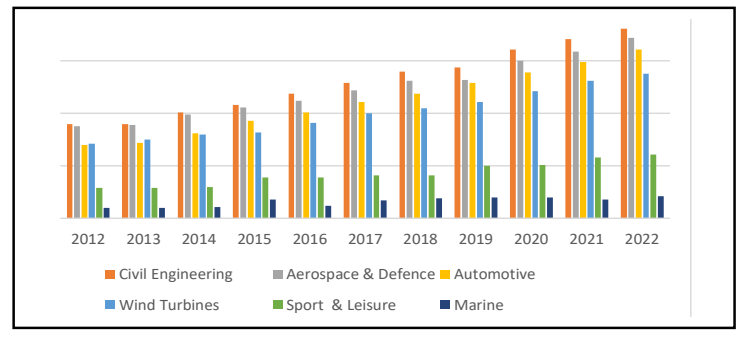

Figure 2 - Global Composites Market 2012-2022

Several steps have been made in automated manufacturing with composite materials in industry. The main areas of automation, covered in many papers, are Automated Fibre Placement (AFP) and Automated Tape Laying (ATL).

AFP and ATL are both automated methods of creating a composite material without the need for the autoclave pressurised heating process [17]. In ATL single large strips of material are handled on a gantry style machine and is useful for large flat shapes. In AFP, multiple smaller strips of composite material are applied in parallel and is useful for complex, detailed structures.

\section{A. Automotive Industry}

\section{1) Composites in the Automotive Industry}

Composites are used in the automotive industry to produce lightweight parts that are durable and strong enough to provide protection in an impact. The weight reduction results in lower fuel consumption which is environmentally advantageous [18]. Materials that do not rust are discussed as another advantage [19][20]. By utilising materials that do not corrode, cars can last longer and do not need to be scrapped so quickly. This is another benefit for the environment.

Common composite materials used in the automotive industry are Carbon and Glass Fibre Reinforced Polymer composites (CFRP and GRP). These materials are used to develop many components of the car including body and chassis parts, steering wheels, dashboards and racing seats. Metal Matrix Composites are also under investigation for use as MMCs exhibit increased tensile strength, thermal conductivity and working temperatures [21].

Developments into the use of composite materials in chassis allowed this concept to be adopted by Formula 1 cars to minimise weight and enhance aerodynamics. Carbon fibre composite material was first introduced by McLaren F1 in 1980 [22]. The following year, John Watson, McLaren driver, lost control of his F1 car, hit a barrier and survived despite the force causing the car's engine and gearbox to be torn from the car. The monocoque protected the driver due to the ability of the carbon fibre material to absorb the energy from the crash. With John Watson walking away from the crash, the worries of carbon fibre F1 cars were eliminated. John Watson is quoted saying "Had I had that accident in a conventional aluminium tub, I suspect I might have been injured because the strength of an aluminium tub is very much less than the carbon tub." [23].

High-end performance development has filtered down into standard automotive manufacturing. Figure 3 shows how carbon fibre composite use is growing in the 
automotive industry and the increase in applications within the vehicle [24].

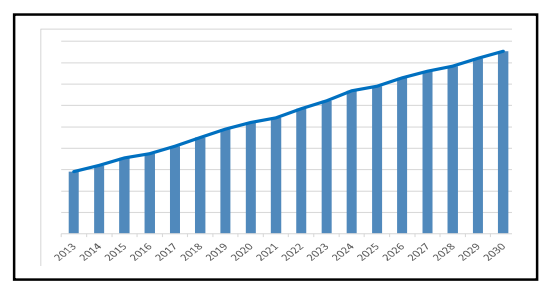

Figure 3 - Trend in Automotive Use of Carbon Fibre Composites

2) Automation in the Automotive Industry

The car manufacturer Audi is committed to investment in automated manufacturing. Their factory in Mexico is designed to use centralised production control, smart sensors, drones and $3 \mathrm{D}$ printing to increase productivity and efficiency [25].

Drones transport steering wheels from one area of the factory to another which relieves humans of a task that is time consuming and unskilled. Key to Audi's concept is that robots will do the bulk of the work and human operators will supervise and handle creative tasks.

The company Voith Composites has worked with Audi to develop a high-speed, automated process for developing carbon fibre automotive components [26].

The Voith Roving Application (VRA) is an advanced Automated Fibre Placement method which lays fibres in a directed fashion and can produce complex composite shapes with high throughput and low waste. The VRA is used by Audi in the development of their A8 CFRP rear panel. The strength produced in the CFRP through specific placement of fibres gives the panel extra strength and rigidity.

\section{B. Aerospace Industry}

\section{1) Composites in the Aerospace Industry}

Composites have been widely used in the aerospace industry over the past several decades. Key elements of their integration are down to the high strength and lightweight obtained from composites [27]. Modern aeroplanes are commonly constructed using aluminium, a lightweight and strong metal. Although aluminium is lightweight, other options to make an aircraft were researched to make them lighter, allowing less fuel consumption and cost saving to occur. Composite materials can provide a similarly strong structure with almost half the weight.

The most common composite material used in the aerospace industry are Carbon Fibre Reinforced Polymers and Glass Fibre Reinforced Polymers [28]. The percentage of composite used within an aircraft has increased year on year, with Boeing going from $12 \%$ to $50 \%$ of composites used by weight in the Boeing 777 [29].

\section{2) Automation in the Aerospace Industry}

Rolls Royce is famously known for their work within the aerospace industry. For decades, Rolls Royce have developed and produced aircraft engines. For new versions of engine, the quality of product and efficiency has increased. Rolls Royce run a state-of-the-art Small Engine
Assembly Line (SEAL) designed to produce turboshaft engines. The production line incorporates 16 separate stations which are all produced to optimise the quality and efficiency of the station [30].

Rolls Royce recently opened a new composites technology hub in the UK. The facility is designed to develop and manufacture fan cases and blades produced from composite materials [31]. The facility will focus on using is carbon-fibre composites, thus helping reduce the overall weight of the aircraft and fuel required to be used. The new engines created with the composite materials are stated to produce $25 \%$ less $\mathrm{CO} 2$ compared to the firstgeneration engines and reduce the fuel consumed also by $25 \%$ [32]. The engines will lighten an aircraft by $700 \mathrm{~kg}$ for a twin-engine system. Rolls Royce continue to develop components with the aim of being quieter, lighter and provide more power with the assistance of composite materials.

\section{Marine Industry}

\section{1) Composites in the Marine Industry}

Composites are widely used within the marine industry in all aspects due to their resistance to corrosion and degradation from the elements [33]. The most common composite material used in the marine industry is Glass Fibre Reinforced Polyester, with $90 \%$ of all recreational boats being built this way [34][35]. Parts built using composites include the hull, the deck and high-performance structural sections.

Development into the use of composites in ship construction led to the first proper 'plastic' boat to be developed in 1946. The surfboat produced was displayed at a show in 1947 [33][36]. The Royal Navy then went on to incorporate composites into their ships, initially with the development of mine countermeasure vessels [35][36].

\section{2) Automation in the Marine Industry}

Airborne is a technology leader in advanced composite component production [37]. Their aim is to reduce the cost of manufacturing low and high volume composite parts by automating and digitalising. Current steps within the production line will be automated creating a building block approach [38]. This allows the automated systems to be configured and placed in the relevant sections within the assembly process. Digitalisation allows the system to learn and optimise a production line.

Airborne is currently working with DAMEN, a shipyard group who design and build seafaring vessels. The two companies, in collaboration with others, are designing and building a composite based vessel. The aim of the project, known as RAMSSES [39], is to "demonstrate the benefits of innovative materials for efficient ship designs" [40]. With the use of composites, vessels could weigh up to $40 \%$ less than steel equivalents, resulting in massive reductions in fuel consumption and emissions. The project partners unveiled a 6 meter-high hull section completely produced using composite materials that they have been working on for roughly three years [41]. With the hull having now been developed, the project can continue and aims to prove the viability of large vessels made from composites as a sustainable and suitable solution. 


\section{Challenges And Future Research DIRECTIONS}

An area of automation discussed in a few papers is prepreg protective film removal [42][43]. Prepreg rolls come with a thin film backing sheet to ensure the sticky resin of the matrix is not tainted with external materials. To use the prepreg material, the thin backing film must be removed. This is a time-consuming process and precise work that needs to be carried out carefully to ensure the prepreg is not damaged. Previous attempts to create a robot to automate the removal of the backing film have been undertaken [42]. The main concept was to use suction to peel the backing film off of a slightly bent corner of prepreg material. The removal of the film in this method proved to be difficult and not possible without an initial corner being manually released from the prepreg material. Once a section had been released it was easy to achieve an automated removal of the film. No paper found identifies a completely successful automated method of prepreg protective film removal.

Another area of automation in the use of composite materials, described in a small number of papers, is automated draping [44][45]. Draping is the overlaying of a prepreg composite material onto a pre-constructed mould. This is a difficult, time consuming process that requires great precision to avoid defects within the finished product. A research group has been investigating a possible solution for this [45] but further investigation into automated draping is required.

\section{CONCLUSION}

In this paper, a review of composite materials and automated manufacturing have been presented. An analysis of automation in composite product manufacturing has also been carried out. From the exponential increase of papers covering composite materials, it is clear that this is an area in the forefront of interest and one that will continue to be developed. Evidence also highlights that automated manufacturing has advanced significantly over time and this has been incorporated into the handling of composites as well. Automation has clearly benefitted industries in their use of composites, however some areas, such as fully automated prepreg protective film removal and draping, require further research.

\section{REFERENCES}

[1] Laura Wood, "Process Automation Market-Growth, Trends, and Forecast (2020-2025)", Business Wire, 2020. [Online] Available:https://www.businesswire.com/news/home/2020 0622005325/en/Global-Process-Automation-IndustryGrowth-Trends-and-Forecast-2020-2025ResearchAndMarkets.com

[2] TechSci Research, "Global Composites Market By Type, By Application, By Manufacturing Process, By Region, Competition Forecast \& Opportunities, 2012-2022", TechSci Research, 2018. [Online] Available: https://www.techsciresearch.com/report /globalcomposites-market-by-type-glass-fiber-carbon-fiber-byapplication-civil-engineering-aerospace- $d$ ' efense-othersby-manufacturing-process-lay-up-injection-moulding-etcby-region-competition-forecast-opportunities/1238.html

[3] Dipen Kumar et al. "Recent progress of reinforcement materials: a comprehensive overview of composite materials", Journal of Materials Research and Technology, $2019 . \quad$ [Online] Available: https://www.sciencedirect.com/science/article/pii/S223878 5419312086

[4] RAHUL REDDY NAGAVALLY, "History of Composite Materials", IRF International Conference, 2019. [Online] Available: https://www.digitalxplore.org/upproc/pdf/240146959633425-30.pdf

[5] Mahadi Hasan et al, "Micromanufacturing of composite materials: areview", International Journal of Extreme Manufacturing, 2019. [Online] Available: https://iopscience.iop.org/article/10.1088/26317990/ab0f74/pdf

[6] Andreas Bjornsson et al, "Automation of Composite Manufacturing Using Off-the-shelf Solutions, Three Cases from the Aerospace Industry", International Conference on Composite Materials, 2015. [Online] Available: https://www.divaportal.org/smash/get/diva2:843138/FULLTEXT01.pdf

[7] Piyoosh Thorietal, "AN APPROACH OF COMPOSITE MATERIALS IN INDUSTRIAL MACHINERY: ADVANTAGES, DISADVANTAGES AND APPLICATIONS", International Journal of Research in Engineering and Technology, 2013. [Online] Available: https://pdfs.semanticscholar.org

15e9c/6bcb41a76e6801acb58e89debcc00381ad4f.pdf

[8] Composites Analysis, "Benefits", CompositesAnalysis, $2010 . \quad$ [Online] Available: http://www.compositesanalysis.com/benefits/

[9] Mansi P. Rajyaguru, "PROS AND CONS OF CARBON FIBER", Research Gate, 2019. [Online] Available: https://www.researchgate.net/publication/334450959PROS ANDCONSOFCARBONFIBER

[10] Mikkel Stein Knudsen et al, "Collaborative Robots: Frontiers of Current Literature", Research Gate, 2020. [Online] Available: https://www.researchgate.net/publication/342347381Colla borativeRobotsFrontiersofCurrentLiterature

[11] ALES VYSOCKY et al, "HUMAN-ROBOT COLLABORATION ININDUSTRY", Semantic scholar, $2016 . \quad$ [Online] Available: https://pdfs.semanticscholar.org/4005/d30d36fffe36ca9c15 e3dad70d75363efd16.pdf

[12] Shirine El Zaatari et al, "Cobot programming for collaborative industrial tasks: Anover view", Research Gate, $2019 . \quad$ [Online] Available:https://www.researchgate.net/publication/33185 5439CobotprogrammingforcollaborativeindustrialtasksAno verview

[13] Christian Parschau et al, "Is automation stealing manufacturing jobs? Evidence from South Africa's apparel industry", $\quad$ Elsevier, $2020 . \quad$ [Online] Available:https://www.sciencedirect.com/ science/article/pii/S0016718520301871

[14] Frohm J. et al, "THE INDUSTRY'S VIEW ON AUTOMATION IN MANUFACTURING", Elsevier, 2006. [Online] Available: https://www.sciencedirect.com/science/article/pii/S147466 7015330925

[15] J"orgen Frohm et al, "Levels of Automation in Manufacturing”, Research Gate, 2020. [Online] Available: https://www.researchgate .net/publication/255793362LevelsofAutomationinManufac turing

[16] Alisha Asquith et al, "Let the robots do it! - Taking a look at Robotic Process Automation and its potential application in digital forensics", Forensic Science International: Reports, 2019.2 [Online] Available:https://www.sciencedirect.com/science/article/pi i/S2665910719300076

[17] Arthur Levy et al, Simulation And Optimization Of The Thermoplastic Automated Tape Placement (ATP) Process, Conference,
Available: 
https://www.researchgate.net/publication

/259669653SimulationAndOptimizationOfTheThermoplast icAutomatedTapePlacementATPProcess, 2012

[18] N. Izzaty et al, "The Implementation of Graphene Composites for Automotive: An Industrial Perspective", IOP Conference Series: Materials Science and Engineering, $2019 . \quad$ [Online] Available: https://iopscience.iop.org/article/10.1088/1757899X/536/1/012133/pdf

[19] Gemma Hatton, How are composites used in motorsport?", Race-car Engineering, 2020. [Online] Available: https://www.racecar-engineering.com/tech-explained/howare-composites-used-in-motorsport

[20] National Composites Network, "Technology Roadmap for Composites in the Automotive Industry", National Composites Network, 2005. [Online] Available: https://avaloncsl.files. $\quad$ wordpress.com $/ 2013 / 01 / \mathrm{ncn}$ roadmap-composites-in-automotive1.pdf

[21] .Ahmed Elmarakbi et al, Novel Composite Materials for Automotive Applications: Concepts and Challenges for Energy Efficient and Safe Vehicles, International Conference on Composite Science and Technology, 2015. [Online] Available: https://core.ac.uk/download/pdf/ 74368201.pdf

[22] G. Savage, Composite Materials Technology in Formula 1 Motor Racing, Honda Racing F1, 2008, [Online]. Available:http://www.formula1-dictionary.net/Big/ Composite $\% 20$ Materials $\% 20$ Technology\%20in $\% 20$ Formula\%201\%20Motor\%20Racing.pdf

[23] Iain Mackenzie, Carbon fibre's journey from race track to hatchback, BBC Technology Reporter, 2011. [Online] Available:https://www.bbc. co.uk/news/technology12691062?print=true

[24] Gina-Marie Oliver, Plastics and composites are reshaping cardesign, IHS report shows, American Chemistry Council, 2014. [Online] Available:https://blog.americanchemistry. com/2014/11/plastics-and-composites-are-reshaping-cardesign-ihs-report-shows/

[25] Florin Ivan, VEHICLES Audi Smart Factory: How Drones, AR And VR Gears Are Building Cars, TECHTHELEAD, 2016. [Online] Available: https://techthelead.com/audismart-factory-how-drones-ar-and-vr-gears-help-build-cars/

[26] Amanda Jacob, Voith demonstrates Industry 4.0 carbon fibre manufacture with Audi part, Inside Composites, 2017. [Online] Available:https://www.insidecomposites.com/ voith-demonstrates-industry-40-carbon-fibre-manufacturewith-audi-part/

[27] Adam Quilteretal, Composites in Aerospace Applications, HIS. [Online] Available:https://ihsmarkit.com/pdf/ Composites-Aerospace-Applicationswhitepaper264558110913046532.pdf.

[28] G.P. Thomas, Composites Used in the Aerospace Industry, AZO Materials, 2013. [Online] Available:https://www. azom.com/article.aspx?Article ID=8152\#:text=An\%20 increasingly $\% 20$ important $\% 20$ innovation $\% 20$ in,barriers $\%$ 20 created $\% 20$ by $\% 20$ using $\% 20$ metals.\&text $=$ Composites $\%$ 20are $\% 20$ essentially\%20materials $\% 20$ made,plastics $\% 20$ re inforced $\% 20$ with $\% 20$ carbon $\% 20$ fibers

[29] Faye Smith, The use of composites in aerospace: Past, presentand future challenges, Avalon Consultancy Services, 2013. [Online] Available: https://avaloncsl.files.wordpress. com/2013/01/avalon-the-use-of-composites-in-aerospaces.pdf

[30] Rolls Royce, Rolls-Royce opens new assembly line for Turboshaft engines, Rolls Royce, 2008. [Online] Available:https://www.rolls-royce.com/media/pressreleases-archive/yr-2008/rr-opens-new-assembly.aspx

[31] Materials Today, Rolls-Royce opens new composites facility, Ma-terials Today, 2020. [Online] Available: https://www.materialstoday.com/ composite-applications/ news/rollsroyce-opens-new-composites-facility-/
[32] Michael Tyrrell, Rolls-Royce opens new composite technology facilityin Bristol, Aerospace Manufacturing, 2020. [Online] Available:https:// www.aero-mag.com/rollsroyce-ultrafan-fan-blades-cases-reduce-weightemissions/\#: :text $=$ A\%20Rolls\%2DRoyce $\% 20$ fan $\% 20$ system,seven $\% 20$ passengers $\% 20$ and $\% 20$ their\%20luggage. \&text=Rolls $\% 2$ DRoyce $\% 20$ has $\% 20$ been $\% 20$ involved,for $\% 20$ parts $\% 20$ within $\% 20$ its\%20engines

[33] Gokdeniz Neser Polymer Based Composites in Marine Use:History and Future Trends, Procedia Engineering, 2017. [Online] Available:https://www.sciencedirect.com/ science/article/pii/S1877705817332460

[34] Adrian Caramatescu et al, REVIEW OF COMPOSITE MATERIALS APPLICATIONS IN MARINE INDUSTRY, "DUNAREA DEJOS" UNIVERSITY OF GALATIFASCICLE XI -SHIPBUILDING, 2019. [Online] Available: https://www.gup.ugal.ro/ugaljournals/index.php /fanship/arti-cle/view/2498/2423

[35] DIMITRIOS-ALEX AND ROSZISIMOPOULOS, Use of Fiber Reinforced Plastics in Ship Construction, 2015. [Online] Available: https://core.ac.uk/download/pdf/38467 591.pdf\#page $=15 \&$ zoom $=100,130,272$

[36] George Marsh, 50 years of reinforced plastic boats, Materials Today, 2006. [Online] Available: https:// www.materialstoday.com/composite-applications/ features/50-years-of-reinforced-plastic-boats/

[37] Airborne, Airborne's vision on Automation and Digitalisation of Composites, Airborne, 2020. [Online] Available: https://www.airborne.com/vision-advancedcomposites/

[38] Airborne, Automating the production of composites, Airborne, 2020. [Online] Available:https://www. airborne.com/automation-solutions-advanced-composites/

[39] DAMEN, A key milestone of RAMSSES project, DAMEN, 2020. [Online] Available:https://www.damen.com/en/ news/2020/07/ramssesprojectreachessignificantmilestoneto wardssustainablecompositeshipconstruction

[40] RAMSSES, Realisation and Demonstration of Advanced Material Solutions for Sustainable and Efficient Ships, INNOVATION AND NETWORKS EXECUTIVE AGENCY, 2020. [Online] Available:https://ec. europa. eu/inea/en/horizon-2020/projects/H2020Transport/Waterborne/RAMSSES

[41] RAMSSES PROJECT, Realisation and Demonstration of Advanced Material Solutions for Sustainable and Efficient Ships, RAMSSES-PROJECT, 2020. [Online] Available: https://www.ramsses-project.eu/

[42] Andreas $\mathrm{Bj}$ ornsson et al, Automated Removal of Prepreg Backing Paper - A Sticky Problem, SAE, 2013. [Online] Available: https://www.diva-portal.org/smash/get/diva2: 656534/FULLTEXT01.pdf

[43] Andreas Bjornsson et al, Low-cost Automation for Prepreg Handling- Two Cases from the Aerospace Industry, SAE 2015. [Online] Available:https://pdfs.semanticscholar.org/ 1442/7fd38bef00ad0f6de2528e1179d9a3c79093.pdf

[44] M. Elkington et al, Automated composite draping: a review, SemanticScholar, 2017. [Online] Available: https://www. semanticscholar.org/paper/Automated-compositedraping\%3A-a-review-Elkington-Ward/f864e87072a58 cbae2a01a0bff371c8f55ea7a7f

[45] L.P. Ellekilde et al, Design of Automated Robotic System for Draping Prepreg Composite Fabrics, Cambridge University Press, 2020. [Online] Available: https:// www.researchgate.net/publication/340900946 DesignofAutomatedRoboticSystemforDrapingPrepregCom positeFabrics 